\title{
Levels and Expression Patterns of Endogenous Hormones during Seed Germination of Dongxiang Wild Rice
}

\author{
Jian Liao ${ }^{1,2}$, Lili Luo ${ }^{1}$, Junhua Zuo ${ }^{1}$, Yaling Chen ${ }^{1 *}$ \\ ${ }^{1}$ Laboratory of Plant Genetic Improvement and Biotechnology, Jiangxi Normal University, Nanchang 330000, China \\ ${ }^{2}$ Jiangxi Biotech Vocational College, Nanchang 330000, China
}

Received: 28 May 2020

Accepted: 6 September 2020

\begin{abstract}
Dongxiang wild rice (Oryza rufipogon Griff, hereafter DXWR), is very precious rice germplasm resource for maintaining genetic diversity of rice germplasm, but it has a strong dormancy property which will hinder the utilization of its germplasm resources. Here, the changes of endogenous hormone and the expression of endogenous hormone gene in DXWR and cultivated rice (9311) were analyzed using enzyme linked immunosorbent quantification and qRT-PCR. The result showed that only $30 \%$ of DXWR germination rate at $36-\mathrm{h}$ and the highest germination rate displayed $83 \%$ at $92-\mathrm{h}$. The content of ABA and JA in DXWR mature seeds was higher than 9311, and the contents of GA and IAA for DXWR only slightly fluctuated during germination. The expression of ABA catabolic genes NCED and $O S A B A 8 O H$ in DXWR fast decreased before germination onset, however GAMYB and DAD (catabolic genes of GA and IAA, respectively) are low expression quantity during seed germination. These results provide important information about the seed dormancy release mechanism of DXWR and provide the theoretical basis for applying this wild rice germplasma.
\end{abstract}

Keywords: Dongxiang wild rice, endogenous hormones, germination rate, gene expression

\section{Introduction}

Seed dormancy is the incapacity of an intact viable seed to complete germination under favorable conditions [1]. The low level of seed dormancy assures quick and even germination of plant seeds, however, it can also result in unwanted early germination at the mother plant (pre-harvest sprouting) and lowered seed quality [2]. On the other hand, high dormancy is regarded as

*e-mail: yaqing620@163.com a negative trait owing to germination retardation and shorten the length of the growing season [1]. Thus, a good understanding of the regulatory mechanism of seed dormancy can provide a theoretical basis for ecological understanding and crop management.

In the past few years, many studies have focused on elucidating the regulation of seed germination and dormancy. Many hypotheses have been proposed and rejected, but the regulatory principle behind changes in dormancy and induction of germination is still a 'black' box $[3,4]$. The majority of proposing mechanisms were related to certain plant hormones. There is considerable evidence that abscisic acid (ABA) and gibberellic acids 
(GA) are the primary phytohormones for seed dormancy establishment and maintenance $[3,5,6]$. Nishimura et al. showed that $A H G 1$, a central negative regulator of ABA response in germination, and upstream components DOG1 constitute an important regulatory system for seed dormancy and germination [7]. Frey et al. showed that the seed of ABA-deficient mutants germinated faster than those of the wild-type [8]. The transgenic rice seeds expressing the positive regulator factors of ABA biosynthesis gene was hypersensitive to ABA during early seedling growth and seed germination [9, 10]. Another important hormone, GA, has an antagonistic effect on the control of dormancy and germination $[9,11]$. Changes in the ABA/GA balance were referred to the expression of dormancy in many species including rice and many cereal crops [4, 12]. Other plant hormones such as indole-3-acetic acid (IAA) and jasmonic acid (JA) also play an important role in inducing and maintaining seed dormancy. Exogenous IAA treatment can delay seed germination, and inhibited pre-harvest sprouting on mother plants $[13,14]$. A recent study revealed that TOR-interacting protein (metabolic gene of IAA) positively regulates seed germination by maintaining the nutritional and hormonal balance [15].

Dongxiang wild rice (Oryza rufipogon Griff., hereafter DXWR), located in Dongxiang county $\left(28^{\circ} 14^{\prime} \mathrm{N}\right.$ latitude and $116^{\circ} 30^{\prime} \mathrm{E}$ longitude), Jiangxi Province, China, is considered to be the most northerly wild rice grown in the world. DXWR contains many excellent traits, such as the resistance to diseases and insect pests, various abiotic stresses, and improvement of biomass accumulation and nutrient quality, and is one of the very precious rice germplasm resource for maintaining genetic diversity of rice germplasm and exploring the excellent traits to modify cultivated rice [16]. It was noted that DXWR possess stronger dormancy than cultivated rice and that this dormancy could be released by after-ripening [17,18]. However, dormancy type and mechanism of DXWR seed are poorly understood. Here, we compared the changes of the endogenous hormones in cultivar and DXWR to investigate the changes in endogenous hormone contents in seed of DXWR during the release of dormancy. In addition, we also examined the expression levels of known genes functioning in biosynthesis and signaling pathway of ABA, IAA, GA and JA. These results provide important information about the seed dormancy release mechanism of DXWR and provide the theoretical basis for applying this wild rice germplasma.

\section{Experimental}

\section{Materials}

The rice (Oryza sativa L.) cultivar 93-11 and the wild rice (DXWR) were grown in the field at Rice Research Institute-Jiangxi Academy of Agricultural Sciences,
Jiangxi, China. The mature seed was harvested, dried to around $20 \%$ water content, then sealed and stored at $-20^{\circ} \mathrm{C}$, keeping the seed dormancy until use in subsequent experiments.

\section{Seed Germination}

Approximately 100 mature and dormant seeds were placed in a filter paper lined Petri dish, soaked in $10 \mathrm{ml}$ of double distilled water, and then cultured in a $28^{\circ} \mathrm{C}$ lightproof chamber, and then Petri dishes for each rice sample were performed. The seed whose embryo breaks through the seed coat is recorded as germination. Germination rates were measured by randomly counting 100 seeds per dish and repeat three Petri dishes. During germination, 50 seeds were collected at $12 \mathrm{~h}$ interval and immediately frozen in liquid nitrogen, until $96 \mathrm{~h}$.

\section{Enzyme Linked Immunosorbent Quantification of Endogenous Hormones}

The frozen rice seeds were ground into powder, and approximately $500 \mathrm{mg}$ powder were homogenized in $5 \mathrm{~mL}$ of ice-cold PBS $(0.01 \mathrm{M}, \mathrm{pH}=7.4)$, and then the homogenates were centrifugated for 5 minutes at $5000 \times \mathrm{g}$ to get the supernatant. ABA, GA3, IAA and JA were analyzed by enzyme linked immunosorbent assay employing monoclonal antibodies, respectively (Abcam, USA) according to the protocol. Standard curves with different ABA, GA3, IAA and JA dilutions were constructed to calculate ABA, GA3, IAA and JA concentrations in the sample, with each measurement repeated 3 times.

\section{RNA Extraction from Rice Endosperm}

Total RNAs from rice endosperm at different treatments were isolated using the SV Total RNA Isolation System (Promega, Peking, China) according to the manufacturer's instructions with some modification. To remove the abundant starch in rice seed, the RNAiso for Polysaccharide-rich Plant Tissue-Takara, Japan-buffer was added to the samples after grinding. Recombinant DNase I (RNase-free) (Takara, Japan) was used to digest contaminating genomic DNA. RNA concentrations were measured spectrophotometrically using a NanoDrop ND-1000 Spectrophotometer (NanoDrop Technologies Inc., Wilmington, DE), and only samples with A260/A280 of 1.8-2.0 were used for further analysis. The RNA quality was checked with an RNA gel for two clear bands of $18 \mathrm{~S}$ and $28 \mathrm{~S}$ rRNAs [19].

\section{Quantitative Real-Time PCR (qRT-PCR)}

From total RNA (5 ug), first-strand cDNA was synthesized with oligo(dT) using the Frist-Strand Synthesis of cDNA kit (Promega, Peking, China). 
Table 1. Sequences of qRT-PCR primers.

\begin{tabular}{|c|c|}
\hline Gene name & Primer sequences 5' to 3' \\
\hline Actin & $\begin{array}{c}\text { forward: GAACTGGTATGGTCAAGGCTG } \\
\text { reverse: ACACGGAGCTCGTTGTAGAAG }\end{array}$ \\
\hline ABA8OH & $\begin{array}{c}\text { forward: CTACTGCTGATGGTGGCTGA } \\
\text { reverse: CCCATGGCCTTTGCTTTAT }\end{array}$ \\
\hline GAMYB & $\begin{array}{l}\text { forward: CTGGGGACACTTCACCTCAT } \\
\text { reverse: ATGATACCGTCGCCAAGAAC }\end{array}$ \\
\hline fOD & $\begin{array}{c}\text { forward: ACCTCATCGACGGGTTCAC } \\
\text { reverse: CGGTTCACGTACTCCTTCTTCA }\end{array}$ \\
\hline fCED & $\begin{array}{c}\text { forward: GCATCCCCAACAGCACATC } \\
\text { reverse: AATAAAGATTGGGAGTGACATATTGG }\end{array}$ \\
\hline & $\begin{array}{c}\text { forward: CTCACCATGAAGTCCATGAGGCTT } \\
\text { reverse: GTTCTCGTAGTCTTGGTCTTGGCT }\end{array}$ \\
\hline
\end{tabular}

Gene-specific primers of starch synthesis related genes used in the subsequent qRT-PCR were listed in Table 1. Additionally, the housekeeping gene Actin was used as internal control to normalize the concentration of cDNA present in each sample. The qRT-PCR was carried out using StepOne TM and StepOne Plus TM Real-Time PCR Systems (ABI-USA), according to the kit manuals accompanying the SYBR ${ }^{\circledR}$ Premix Ex Taq (Takara, Dalian, China). The relative expression levels were calculated by the method of $2^{-\Delta \mathrm{CT}}[20]$.

\section{Results and Discussion}

\section{Germination Rates of Wild Rrice (DXWR) and 9311}

According to germination test results (Fig. 1), although all seeds started to germinate after $24 \mathrm{~h}$ rehydration, we observed significant differences between cultivar 9311 and wild rice. 9311 showed the $83 \%$ germination rate within 36 -h imbibition and the highest germination rate (91\%) within $72-\mathrm{h}$ imbibition,

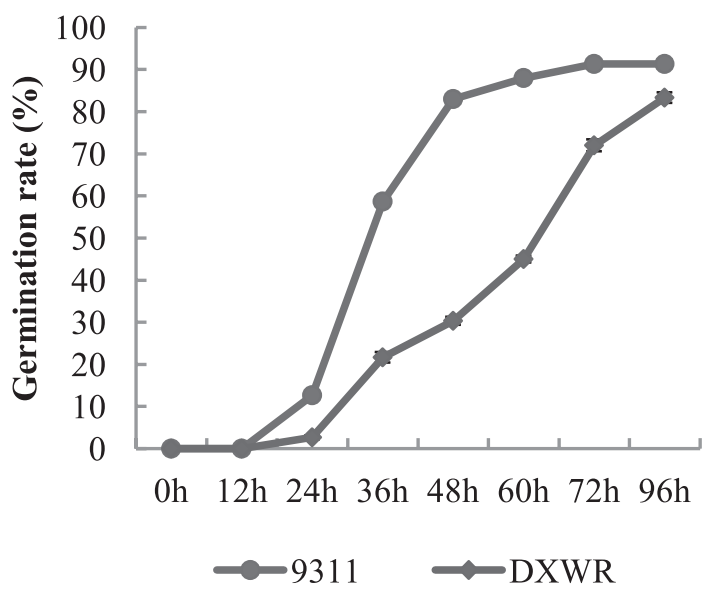

Fig. 1. Germination rates of wild rice (DXWR) and cultivated rice (9311). in contrast, only $30 \%$ of wild rice at $36-\mathrm{h}$ and the highest germination rate displayed $83 \%$ at $92-\mathrm{h}$. According to the method described by Wan et al. [21], the germination percentage was used to evaluate the dormancy levels, deep dormant, medium dormant and non-dormant displayed $<2 \%, 50 \%-80 \%$ and $>80 \%$ germination after four days' imbibition, respectively. So, the DXWR was regarded as medium dormant. Hilhorst et al. described that some seeds with physiological dormancy may not germinate under favorable conditions, but the seeds with medium dormant can germinate slowly in a narrow light temperature range [22]. The germination rate of DXWR is uniform and slow during $24 \mathrm{~h}-96 \mathrm{~h}$ imbibition, indicating that the dormancy of DXWR seed was non-physical dormancy.

The Levels of Endogenous Hormones in Wild Rice (DXWR) and Cultivated Rice (9311)

Since the germination rate of rice is closely related to the levels of endogenous hormones, we quantified ABA, GA, IAA and JA in 9311 and DXWR at different seed germination time points. Researches suggested that seed dormancy is partly depended on the level of ABA contained in mature seeds $[6,23]$. The content of ABA in DXWR mature seeds was higher than 9311 (Table 2). During the germination of 9311 seeds, the lowest ABA content was $24 \mathrm{~h}$, and the seeds began to germinate at this time point, consistent with previous studies which have revealed the loss of dormancy and germination of grain seeds were related to the decrease of seed ABA level during imbibition [4, 12]. Interestingly, during 9311 and DXWR seed germination, the change trend of JA content is similar to ABA content, suggested that JA has an inhibitory effect on the germination process which can support by the exogenous JA application delays seed germination [23].

In contrast, a significant peak of GA and IAA occurred after the germination onset at $36 \mathrm{~h}$ for 9311, and the contents of GA and IAA for DXWR only slightly fluctuated (Table 2), which coincided with germination 
Table 2. The content of endogenous hormones in wild rice (DXWR) and cultivated rice (9311).

\begin{tabular}{|c|c|c|c|c|c|c|c|c|}
\hline \multirow{2}{*}{ Time Content } & \multicolumn{2}{|c|}{ ABA $(\mathrm{ng} / \mathrm{mL})$} & \multicolumn{2}{c|}{ IAA $(\mu \mathrm{mol} / \mathrm{L})$} & \multicolumn{2}{c|}{ GA $(\mathrm{pmol} / \mathrm{L})$} & \multicolumn{2}{c|}{ JA $(\mathrm{pmol} / \mathrm{L})$} \\
\cline { 2 - 9 } & 9311 & DXWR & 9311 & DXWR & 9311 & DXWR & 9311 & DXWR \\
\hline $0 \mathrm{~h}$ & $13.9 \pm 0.9$ & $17 \pm 0.4$ & $3.7 \pm 0.1$ & $4.4 \pm 0.2$ & $23.1 \pm 1.1$ & $29.6 \pm 0.9$ & $478 \pm 22.6$ & $495 \pm 25.6$ \\
\hline $12 \mathrm{~h}$ & $13.9 \pm 0.3$ & $17.5 \pm 0.3$ & $3.8 \pm 0.1$ & $4.5 \pm 0.2$ & $18.1 \pm 1.0$ & $22.0 \pm 0.9$ & $386.9 \pm 23.3$ & $547.7 \pm 6.8$ \\
\hline $24 \mathrm{~h}$ & $12.5 \pm 0.7$ & $14.4 \pm 0.7$ & $2.9 \pm 0.1$ & $4.4 \pm 0.1$ & $24.7 \pm 0$ & $30.3 \pm 1.5$ & $476.3 \pm 0.6$ & $467.3 \pm 28.6$ \\
\hline $36 \mathrm{~h}$ & $14.9 \pm 0.5$ & $18.5 \pm 1.3$ & $4.9 \pm 0.2$ & $4.8 \pm 0.3$ & $36.3 \pm 1.2$ & $35.6 \pm 1.2$ & $555 \pm 15.2$ & $602.4 \pm 7.5$ \\
\hline $48 \mathrm{~h}$ & $15.6 \pm 0.8$ & $19.8 \pm 1.3$ & $3.8 \pm 0.1$ & $4.9 \pm 0.1$ & $31.9 \pm 1.7$ & $33.4 \pm 0.4$ & $512.7 \pm 16.6$ & $640.2 \pm 29.4$ \\
\hline $60 \mathrm{~h}$ & $19.6 \pm 1.2$ & $18.4 \pm 1.3$ & $4.4 \pm 0.1$ & $4.7 \pm 0.1$ & $24.7 \pm 0.3$ & $35.9 \pm 1.3$ & $487.0 \pm 26.3$ & $606.0 \pm 10.1$ \\
\hline $72 \mathrm{~h}$ & $16.1 \pm 0.4$ & $17.4 \pm 1.2$ & $4.2 \pm 0.2$ & $4.3 \pm 0.1$ & $27.8 \pm 0.9$ & $33.2 \pm 1.0$ & $517.9 \pm 12.8$ & $545.5 \pm 5.3$ \\
\hline $96 \mathrm{~h}$ & $13.4 \pm 0.2$ & $18.4 \pm 0.9$ & $3.9 \pm 0.1$ & $4.9 \pm 0.1$ & $27.8 \pm 1.6$ & $30.6 \pm 0.9$ & $507.2 \pm 21.8$ & $541.8 \pm 16.6$ \\
\hline
\end{tabular}

phenotypes of these two rice varieties (Fig. 1). Xiao et al. found that the content of IAA in the embryo gradually increased during seed germination, and then reach a maximum at $12 \mathrm{~h}$, but then decreased at $48 \mathrm{~h}$ [24]. Jia et al. found that GA biosynthesis and signaling transduction specifically act on seed dormancy release
[25]. Several physiological and genetic analyses have demonstrated the requirement of GA for germination; GA can promote seed germination through enhancing the growth potential of the embryo and overcoming the mechanical barriers imposed by covering layers surrounding embryo $[4,12]$.
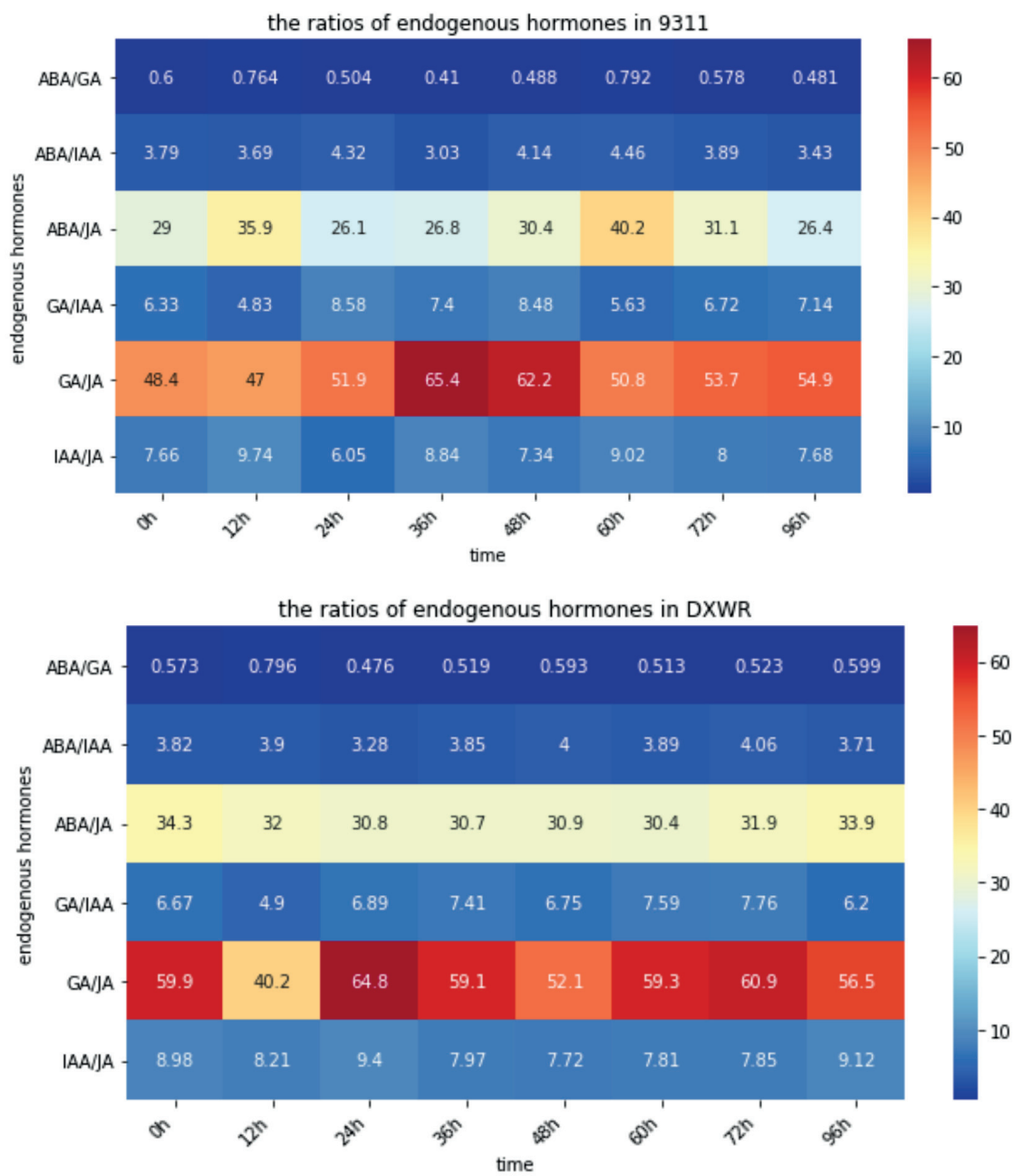

Fig. 2. The ratios of endogenous hormones (ABA, IAA, GA and JA) in wild rice (DXWR) and 9311. 
The Ratios of ABA/GA, ABA/IAA and ABA/JA in Wild Rice (DXWR) and 9311

Dynamic variations of the $\mathrm{ABA} / \mathrm{GA}$ ratio during germination showed that DXWR had a similar ratio with 9311 during $24 \mathrm{~h}$ imbibition, but significantly higher ratio than 9311 during $24 \mathrm{~h}-48 \mathrm{~h}$ imbibition (Fig. 2), consistent with previous studies showed that a high $\mathrm{ABA} / \mathrm{GA}$ ratio is critical for the induction of maturation and germination suppression in early seed development programming [25]. In our results, the ABA/IAA ratio for DXWR only slightly fluctuated, but one ratio slack at $36 \mathrm{~h}$ and two ratio peaks at early and late stages of seed germination for 9311 were observed (Fig. 2), suggesting IAA can promote seed germination. Shuai et al. reported that exogenous IAA treatment represses seed germination by enhancing $\mathrm{ABA}$ biosynthesis, while impairing GA biogenesis [26]. In addition, the ratio of ABA/
JA for DXWR almost no change, on the contrary, after an initial increased ABA/JA for 9311 and then decreased again before the germination onset (12 h) (Fig. 2). At the later stage of germination, $\mathrm{ABA} / \mathrm{JA}$ ratio reached its peak value, and then decreased rapidly to the lowest value, similarly with Wilen et al. reported the ABA in combination with JA resulted in a higher degree of seed germination inhibition at $23^{\circ} \mathrm{C}$ in maize, wheat and cornflower than either growth regulator applied separately [27].

The DXWR has the similar GA/IAA ratio with 9311 during $24 \mathrm{~h}$ imbibition, but the GA/IAA ratio for 9311 was significantly higher than DXWR during $24 \mathrm{~h}-48 \mathrm{~h}$ imbibition (Fig. 2). In addition, the GA/IAA ratio for DXWR decreased to the lowest value at $12 \mathrm{~h}$, during 24h-96h imbibition, the GA/IAA ratio only slightly fluctuated and was closed to the GA/IAA ratio before germination (Fig. 2). GA can promote the synthesis of IAA by tryptophan, meanwhile, it can inhibit the

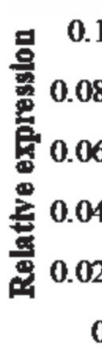

Oh $12 \mathrm{~h} 24 \mathrm{~h} 36 \mathrm{~h} 48 \mathrm{~h} 60 \mathrm{~h} 72 \mathrm{~h} 84 \mathrm{~h}$
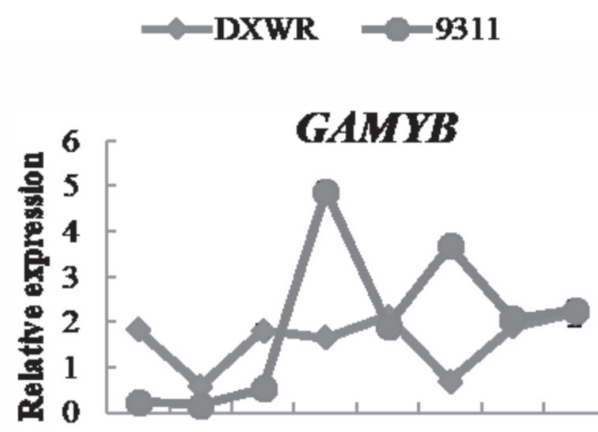

Oh 12h 24h 36h 48h 60h 72h 84h

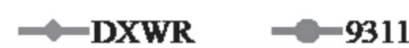

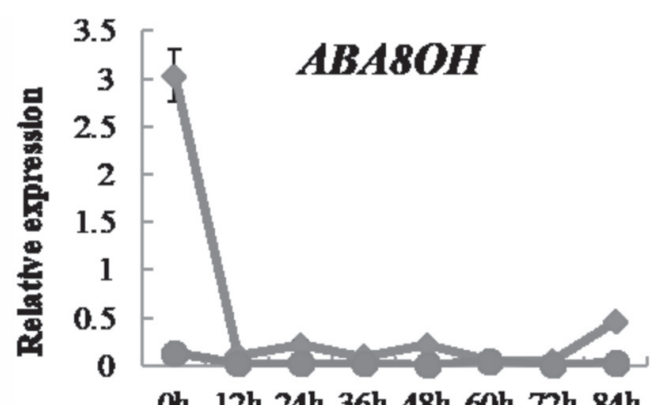

0h $12 \mathrm{~h} 24 \mathrm{~h} 36 \mathrm{~h} 48 \mathrm{~h}$ 60h $72 \mathrm{~h} 84 \mathrm{~h}$

- DXWR -9311

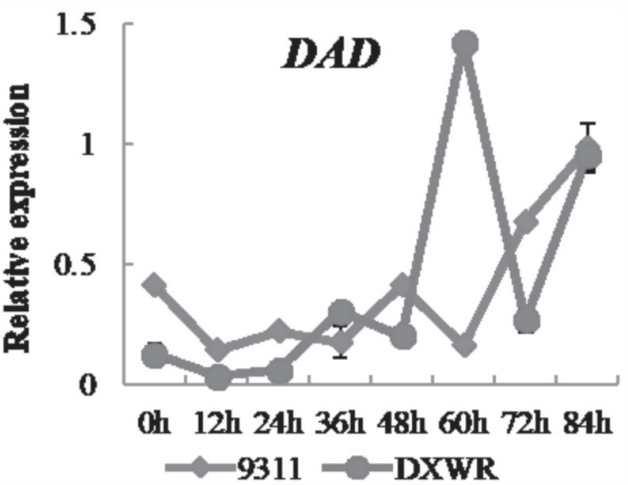

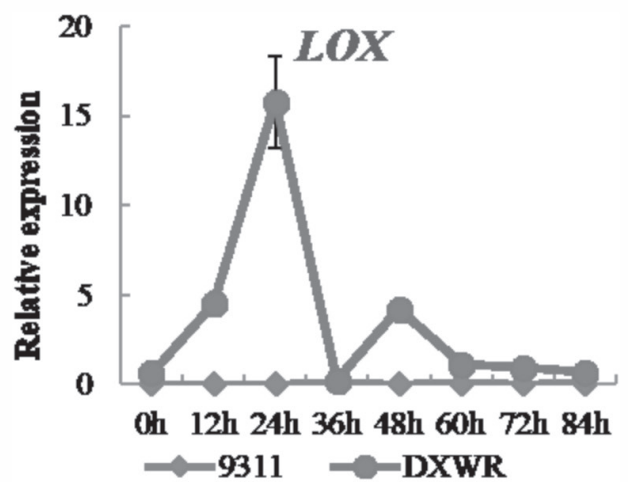

Fig. 3. qRT-PCR analysis expression of endogenous hormones metabolism genes in wild rice (DXWR) and 9311. 
activity of IAA-oxidase and peroxidase, promote the synthesis of IAA, inhibit its degradation and increase the content of IAA [12].

\section{Expression of ABA, GA, IAA and JA Metabolism Genes in DXWR and 9311}

Differences in expression of key endogenous hormone metabolism genes may lead to differences in seed dormancy. Thus, we analyzed the expression of genes connected with ABA, GA, IAA and JA biosynthesis and catabolism using qRT-PCR during seed germination. The main catabolic pathway of $\mathrm{ABA}$ is the reaction catalyzed by OsABA8OH (ABA 80-hydroxylase), and the key enzyme that regulations ABA biosynthesis is NCED (9-cis-epoxycarotenoid dioxygenase) [28, 29]. The $O s A B A 8 O H$ genes is a rate-limiting step in the process of $\mathrm{ABA}$ biosynthesis [28]. OsABA8OH has 3 homologous in rice, among which $\mathrm{OSABA8OH2}$ is mainly expressed during seed development [30]. The expression of NCED and OsABA8OH genes was also affected by after-ripening. According to the results obtained by qRT-PCR, there is low transcription level of NCED and $O S A B A 8 O H$ in 9311 and it did not significantly change during seed germination. In contrast, the expression of ABA catabolic genes NCED and OsABA8OH in DXWR fast decreased before germination onset and the latter peaked again at 96h (Fig. 3). Many studies showed that the transcript levels of $O S A B A 8 O H$ in imbibed grains were strongly increased as a result of post harvest storage [31, 32], and the expression of the NCED and $O s A B A 8 O H$ homologues in imbibed grains was observed at very low, constant level [31, 33].

The gene product of $G A M Y B$ was critical for the induction of $\alpha$-amylase in aleurone, and $G A M Y B$ is the first identified GA signaling protein that regulates other transcription factors, and is a positive regulators of seed dormancy [34]. Liu et al. found that the expression of $G A M Y B$ peaked at early, middle, and late stages of seed development for deep dormant, medium dormant, and non-dormant, respectively, GAMYB has a positive correlation with the gene expression time [35]. Expression analysis revealed the transcript of GA and IAA metabolism gene $G A M Y B$ and $D A D$ in 9311 had two peaks occurring at $48 \mathrm{~h}$ and $72 \mathrm{~h}$ respectively. In contrast, for DXWR both the GAMYB and DAD are low expression quantity during seed germination (Fig. 3), indicating that ABA and GA crosstalk during seed dormancy.

JA is synthesized in a series of steps, beginning with the release of linolenic acid (LA) and then converted to 13-hydrogen peroxide by lipoxygenase (LOX) [36]. It is low expression of LOX in 9311 and it almost no change during seed germination. By contrast, the expression of $L O X$ in DXWR was increasing prior to $24 \mathrm{~h}$ and firstly peaked $24 \mathrm{~h}$, then quickly drop to the lowest level at $48 \mathrm{~h}$ and the latter peaked again at $60 \mathrm{~h}$ (Fig. 3). At present, research on JA function is mainly about its resistance to diseases, insect pests and various abiotic stresses, but the research on seed dormancy is less. In this research, we found JA, as a new plant growth regulator, has an inhibitory effect on the germination process, and it had some similar physiological effects to ABA.

\section{Conclusions}

Seed dormancy is a quantitative trait. Primary dormancy was induced at seed maturity and reached a higher level in freshly harvested seed. We found only $30 \%$ of DXWR germination rates at $36-\mathrm{h}$ and the highest germination rate displayed $83 \%$ at 92-h, regarded as medium dormant. The content of ABA and JA in DXWR mature seeds was higher than 9311. Interestingly, during 9311 and DXWR seed germination, the change trend of JA content is similar to ABA content, suggested that JA has an inhibitory effect on the germination process. The ABA/GA ratio showed that DXWR had a significantly higher ratio than 9311 during $24 \mathrm{~h}-48 \mathrm{~h}$ imbibition, revealed that a high ABA/GA ratio is critical for the induction of maturation and germination suppression. The expression of ABA catabolic genes $N C E D$ and $O S A B A 8 O H$ in DXWR fast decreased before germination onset, however $G A M Y B$ and $D A D$ are low expression quantity during seed germination, showed that seed germination is related to the regulation of endogenous hormone catabolic genes.

\section{Acknowledgements}

This research was supported by the Major Projects of the Natural Science Foundation of China (Grant Nos. 31800640) and Young talents of Jiangxi Normal University, awarded to Ph.D Yaling Chen.

\section{Conflict of Interest}

The authors declare no conflict of interest.

\section{References}

1. BASSEL G.W. To grow or not to grow? Trends in Plant Science, 21, 498, 2016.

2. SIMSEK S., OHM J.B., Lu H, RUGG M., BERZONSKY W., ALAMRI M.S., MERGOUM M. Effect of pre-harvest sprouting on physicochemical changes of proteins in wheat. Journal of The Science of Food Agriculture, 94, 205, 2014

3. GUBLER F., MILLAR A.A., JACOBSEN J.V. Dormancy release, ABA and pre-sprouting. Current Opinion in Plant Biology, 8 (2), 183, 2005.

4. SHU K., LIU X.D., XIE Q., HE Z.H. Two faces of one seed: hormonal regulation of dormancy and germination. Molecular Plant, 9, 34, 2016.

5. GRAEBER K., NAKABAYASHI K., MIATTON E., 
LEUBNER-METZGER G., SOPPE W.J. Molecular mechanisms of seed dormancy. Plant Cell and Environment, 35, 1769, 2012.

6. WANG Y.M., WANG L.J., YAO B., LIU Z., LI F. Changes in ABA, IAA, GA3, and ZR levels during seed dormancy release in Idesia polycarpa maxim from Jiyuan. Polish Journal of Environmental Studies, 27 (4), 1833, 2018.

7. NORIYUKI N., WATARU T., MORESCO J.J., YUKI H., KOUJI S., NAHOMI K., TOMOKO I., TOSHINORI K., JULIAN I.S., JOHN R.Y., TAKASHI H., TOSHIMASA Y. Control of seed dormancy and germination by dogl-ahgl $p p 2 c$ phosphatase complex via binding to heme. Nature Communications, 9 (1), 2132, 2018.

8. FREY A., EFFROY D., LEFEBVRE V., SEO M., PERREAU F., BERGER A., SECHET J., TO A., NORTH H.M., MARION-POLL A. Epoxycarotenoid cleavage by NCED5 fine-tunes ABA accumulation and affects seed dormancy and drought tolerance with other NCED family members. Plant Journal, 70, 501, 2011.

9. NONOGAKI M., SALL K., NAMBARA E., NONOGAKI $\mathrm{H}$. Amplification of ABA biosynthesis and signaling through a positive feedback mechanism in seeds. Plant Journal, 78, 527, 2014.

10. KIM H., HWANG H., HONG J.W., LEE Y.N., AHN I.P., YOON I.S., YOO S.D., LEE S., LEE S.C., KIM B.G. A rice orthologue of the ABA receptor, OSPYL/RCAR5, is a positive regulator of the ABA signal transduction pathway in seed germination and early seedling growth. Journal of Experimental Botany, 63 (2), 1013, 2012.

11. GAIROLA S., EL-KEBLAWY, A. Seed germination behaviour of five resedaceae species from arid arabian desert: gibberellic acid and light effects. Plant Biosystems, $1,2019$.

12. TUAN P.A., ROHIT K., REHAL P.K., TOORA P.K., AYELE B.T. Molecular mechanisms underlying abscisic acid/gibberellin balance in the control of seed dormancy and germination in cereals. Frontiers in Plant Science, 9, 668, 2018.

13. PARK J., KIM Y.S., KIM S.G., JUNG J.H., WOO J.C., PARK C.M. Integration of auxin and salt signals by the NAC transcription factor NTM2 during seed germination in Arabidopsis. Plant Physiology, 156, 537, 2011.

14. LIU X., ZHANG H., ZHAO Y., FENG Z., LI Q., YANG H.Q., LUAN S., LI J., HE Z.H. Auxin controls seed dormancy throughstimulation of abscisic acid signaling by inducing ARF-mediated $\mathrm{ABI} 3$ activation in Arabidopsis. Proceedings of the National Academy of Sciences of the United States of AmericA, 110, 15485, 2013.

15. SALEM M.A., GIAVALISCO P. Regulatory-associated protein of tor $1 \mathrm{~b}$ (raptorlb) regulates hormonal switches during seed germination in arabidopsis thaliana. Plant Signaling and Behavior, 14 (7), 1, 2019.

16. XIE J., AGRAMA H.A., KONG D., ZHUANG J., HU B., WAN Y., YAN W. Genetic diversity associated with conservation of endangered Dongxiang wild rice (Oryza rufipogon). Genetic Resources and Crop Evolution, 57, 597, 2010.

17. WAHEED A., AHMAD H., ABBASI F.M. Different treatment of rice seed dormancy breaking, germination of both wild species and cultivated varieties (Oryza sativa L). Journal of Materials and Environmental Science, 3 (3), 551, 2012.

18. XU H.H., LIU S.J., SONG S.H., WANG W.Q., MØLLERC I.M., SONG S.Q. Proteome changes associated with dormancy release of Dongxiang wild rice seeds. Journal of
Plant Physiology, 206, 68, 2016.

19. AFSHAR-MOHAMMADIAN M., REZADOOST M.H., FALLAH S.F. Comparative analysis and innovation of a simple and rapid method for high-quality rna and dna extraction of kiwifruit. Methodsx, 5, 352, 2018.

20. JAIN M., NIJHAWAN A., TYAGI A.K., KHURANA J.P. Validation of housekeeping genes as internal control for studying gene expression in rice by quantitative real time PCR. Biochemical and Biophysical Research Communications, 345 (2), 646, 2006.

21. WAN J., NAKAZAKI T., KAWAURA K., IKEHASHI H. Identification of marker loci for seed dormancy in rice (Oryza sativa L). Crop Science, 37, 1759, 1997.

22. HILHORST H.W.M. Definitions and hypotheses of seed dormancy. Annual Plant Reviews: Seed Development, Dormancy and Germination. 27, 50, 2007.

23. KANNO Y., JIKUMARU Y., HANADA A., NAMBARA E., ABRAMS S.R., KAMIYA Y., SEO M. Comprehensive hormone profiling in developing arabidopsis seeds: examination of the site of ABA biosynthesis, ABA transport and hormone interactions. Plant and Cell Physiology, 51, 1988, 2010.

24. XIAL H.M., CAI W. J., YE T.T., DING J., FENG Y.Q. Spatio-temporal profiling of abscisic acid, indoleacetic acid and jasmonic acid in single rice seed during seed germination. Analytica Chimica Acta, 1031, 119, 2018.

25. JIA Z., ZHAO B., LIU S., LU Z., CHANG B., JIANG H., CUI H., HE Q., LI W., JIN B., WANG L. Embryo transcriptome and mirna analyses reveal the regulatory network of seed dormancy in ginkgo biloba. Tree Physiology, 2020, DOI: 10.1093/treephys/tpaa023.

26. SHUAI H., MENG Y., LUO X., CHEN F., ZHOU W., DAI Y., QI Y., DU J., YANG F., LIU J., YANG W., SHU $\mathrm{K}$. Exogenous auxin represses soybean seed germination through decreasing the gibberellin/abscisic acid (GA/ ABA) ratio. Scientific Reports, 7, 12620, 2017.

27. WILEN R. W., EWAN B. E., GUSTA L. V. Interaction of abscisic acid and jasmonic acid on the inhibition of seed germination and the induction of freezing tolerance. Canadian Journal of Botany, 72 (7), 1009, 1994.

28. KALLADAN R., LASKY J.R., SHARMA S., KUMAR M.N., JUENGER T.E., MARAIS D.L.D., VERSLUES P.E. Natural variation in 9-cis-epoxycartenoid dioxygenase 3 and ABA accumulation. Plant Physiology, 179, 1620, 2019.

29. SURIYASAK C., HARANO, K, TANAMACHI, K., MATSUO K., TAMADA A., IWAYA-INOUE M., ISHIBASHI Y. Reactive oxygen species induced by heat stress during grain filling of rice (Oryza sativa L.) are involved in occurrence of grain chalkiness. Journal of Plant Physiology, 216, 52, 2017.

30. HU Q., LIN C., GUAN Y., SHETEIWY M.S., HU W., HU J. Inhibitory effect of eugenol on seed germination and pre-harvest sprouting of hybrid rice (oryza sativa L.). Scientific Reports, 7 (1), 5295, 2017.

31. JACOBSEN J.V., BARRERO J.M., HUGHES T., JULKOWSKA M., TAYLOR J.M., XU Q., GUBLER F. Roles for blue light, jasmonate and nitric oxide in the regulation of dormancy and germination in wheat grain (Triticum aestivum L). Planta, 238, 121, 2013.

32. ISHIBASHI Y., AOKI N., KASA S., SAKAMOTO M., KAI K., TOMOKIYO R., WATABE G., YUASA T., IWAYA-INOUE M. The interrelationship between abscisic acid and reactive oxygen species plays a key role in barley seed dormancy and germination. Frontiers in Plant Science, 8, 275, 2017.

33. BARRERO J.M., JACOBSEN J.V., TALBOT M.J., WHITE 
R.G., SWAIN S.M., GARVIN D.F., GUBLER F. Grain dormancy and light quality effects on germination in the model grass Brachypodium distachyon. New Phytologist, 193, 376, 2012.

34. RAVINDRAN P., VERMA V., STAMM P., KUMAR P.P. A novel RGL2-DOF6 complex contributes to primary seed dormancy in Arabidopsis thaliana by regulating a GATA transcription factor. Molecular Plant, 10, 1307, 2017.

35. LIU Y., FANG J., XU F., CHU J., YAN C., SCHLÄPPI
M.R., WANG Y., CHU C. Expression patterns of ABA and GA metabolism genes and hormone levels during rice seed development and imbibition: a comparison of dormant and non-dormant rice cultivars. Journal of Genetics and Genomics, 41, 327, 2014.

36. ZHOU G., QI J., REN N., CHENG J., MATTHIAS E., MAO B., LOU Y. Silencing OsHI-LOX makes rice more susceptible to chewing herbivores, but enhances resistance to a phloem feeder. Plant Journal, 60 (4), 638, 2009. 